\title{
Prologue
}

\section{Research on Teaching in English: Secondary and Higher Education. Where Have We Been and Where Are We Going?}

\author{
Teresa Morell, Marian Alesón and María Tabuenca \\ University of Alicante \\ mt.morell@es / aleson@ua.es / maria.tabuenca@ua.es
}

\begin{abstract}
At the end of the first decade of this new millennium, it is time to reflect on English Language Teaching (ELT) research and practice, due to the fact that English has become the global lingua franca and inevitably the communicative use of this global language has been promoted. Throughout its history, English Language Teaching (henceforth, ELT) and its research has been influenced by the way language, in general, has been understood, thought to be learned and needed to be used in given time periods. In other words, the ideas defining language (linguistic paradigms), the leading theories attempting to determine how it is acquired and the particular social demand for its implementation have determined the type of research carried out to find out how English can be taught best in the particular temporal and social context.

In this introduction of the special issue on ELT we reflect on the progress of English teaching research mainly in higher education. We start with a brief review of the field by examining the three most influential factors, i.e., the linguistic, psychological and sociological realms or paradigms that have determined its research and practice to the present day. Secondly, we examine the significant developments in the state of the English language, recent European educational and language legislation, as well as the technological advances that have also played a predominant role in characterizing ELT methodology today. As is evidenced by the articles found in this volume of "Research on Teaching in English: Secondary and Higher Education", many studies have focused on the pedagogical procedures used in Spanish tertiary education, influenced by the creation of the European Higher Education Area (EHEA) and the Common European Framework of Reference for Languages (CEFR), to facilitate the use of language for the academic and future professional lives of English language learners.
\end{abstract}


Thus, this prologue, which aims to describe where research in ELT has been and where it is going, has been divided into the following three main sections: 1. The linguistic, psychological and social realms that have influenced ELT until present day, 2. ELT in European higher education today: influential legislations, technological advances, and methodologies, and 3.The ELT research contributions of this special issue

\section{The linguistic, psychological and social realms that have influenced ELT until present day}

To present a brief state of the art of ELT research and practice today that takes into account the historical and present developments of the field, we have put together the following outline of the linguistic, psychological and social realms that have played an important role in establishing the study of English and its instruction as it is currently understood.

\subsection{The linguistic paradigms - the nature of language}

The linguistic paradigms, or the concepts underlying the attitudes towards the nature of language during the past century was expertly related by professor Enrique Alcaraz (1990) in his renowned Tres paradigmas de la investigación lingüistica. In this groundbreaking publication each of the following predominant linguistic paradigms: structuralism, generativism and pragmatics are described as linguistic frameworks with a relative degree of similar theoretical thoughts and views for the interpretation and investigation of language. Each of them has contributed basic theories, fundamental texts and concepts, as well as key terms which have served as sources or instruments for research in teaching English.

At the beginning of the twentieth century, the traditional grammar emphasis on the historical and comparative value of language was displaced by the tendency of structuralism to describe the structure of language at particular points in time. The terms "Langue" and "parole" describe the use of a language at a particular time and the actual utterances speakers produce, respectively. In other words, langue is the underlying system on the basis of which speakers are able to understand and produce speech, whereas parole is always an individual realization of the system. This innovative focus on language was attributed to Ferdinand de Saussure in Europe and to Leonard Bloomfield in the United States. Saussure's Course in General Linguistics (1916) and Bloomfield's Language (1933) greatly influenced the linguistic perspectives of the first half of the twentieth century. Both European and North American structural theories aimed to describe language; the units of language and their relations were the fundamental concepts of structuralism on both sides of the ocean. Although American structuralism gave more importance to the units of language and European structuralism emphasized the relations between the units, they both saw language as a system of formal patterning, especially in phonology and grammar. The formal patterning of syntagmatic structures (e.g., affirmative, negative and interrogative), as well as the behaviourists view (that individuals learned if they were stimulated in such a way to produce a conditioned response, and if this stimulus response reaction was repeated it would become 
a habit), led to the popular substitution tables and drills in language teaching. These drills were used as a means to explain and practice grammatical patterns. In Lado's Language Teaching: A Scientific Approach (1964) there are detailed explanations of the wide range of pattern drills (substitution drills, transformation drills, addition drills, etc.) and their use within the four major language skills- listening, reading, writing and speaking -that stemmed from the structural paradigm and that were used by the audiolingual and situational approaches in the mid-twentieth century. In fact, these tables and drills were and can still be found in course books with a structural syllabus.

Generativists, much like structuralists, analyzed the surface syntactic patterns, but also the underlying syntactic structures that were regarded as semantic units of the sentence. Although Generativists can be considered structuralists as well, they differ in their ultimate goal. In essence, structuralists aim to describe observable linguistic behaviour, whereas generativists strive to explain the linguistic competence or grammar used by native speakers, i.e, the innate capacity we all have to produce language. The generative transformational approach, which was brought forth in Noam Chomsky's Syntactic Structures (1957), concerned the possibility that there may be a connection between 'competence', the deep level rules (later referred to as I-language - internal language), and 'performance, the surface structures (later referred to as E-language - external language). Unlike the behaviourists influence upon structuralism, cognitivism together with the generative view of language held that learning occurred when concepts were presented in a meaningful manner, which involved affective and procedural factors. Although Generativists, especially Chomsky, claimed not to have anything to say to help English language teachers, they undoubtedly caused a great change in the approaches used for instruction. In the mid twentieth century many educational methodologies shifted towards a more affective approach taking into account factors such as motivation, intelligence, and creating appropriate environments for learning found in humanistic approaches (e.g., Total Physical Response and the Silent Way).

The advent of the Pragmatic linguistic paradigm in the latter part of the twentieth century brought about a change in focus from the formal sentence level to the functional text based unit. In Halliday's words, by functional we mean language that is doing some job in some context, as opposed to isolated words and sentences. A text is a semantic unit that together with its context transmits meaning. In other words, we are not only referring to what is said or written, but also to other non-verbal simultaneous occurrences - the total environment in which a text unfolds. If we examine the characteristic dichotomies of structuralism and generativism, namely "langue and parole" of the former and "performance and competence" of the latter, we note that pragmatics underlines the "parole" and the "competence", i.e., the use of the language for communication. There has been an obvious shift from the structures and the implicit rules of the language to how the speakers make use of it and communicate. When we refer to competence it is not only to the linguistic, but also to the communicative competence- the capacity to transmit and interpret messages and to negotiate meaning in an interpersonal manner within a specific context. Much like generativism, pragmatics views language more as a psychological study than a syntactic study and it relates language to one particular aspect of human experience, namely that of social interaction. 
This focus on interpersonal communication that characterizes pragmatics, the predominant linguistic paradigm of the past three decades, has been highly influential in the establishment and development of the communicative approach in ELT. In classrooms, materials and activities are authentic or try to reflect real-life situations and demands. The content of the courses not only include linguistic structures, but also semantic notions and social functions. The students often work in pairs or in groups to transfer and negotiate meaning, and they practice through role-playing. Another approach to ELT that has derived from this communicative focus in the past two decades is task-based learning. Much like the Communicative approach, task-based learning concentrates on the use of the language, but its main focus is not only the learner, but also the learning process. Literature on ELT from the late 1980s and early 1990s claims that second language (L2) learning is a non-linear process and therefore, does not need pre-selected, pre-sequenced language inputs, but requires the creation of conditions in which learners engage in meaningful interaction. The belief is that learning occurs when the students are involved in understanding, saying and doing something with the language, which in essence can be interpreted into tasks with a pedagogic purpose.

\subsection{The psychological realms - how language is learnt}

To provide a more complete, although concise, state of the art of ELT it is necessary to go beyond the linguistic paradigms, which have apparently been influenced by the schools of behavioural and cognitive psychology, to the currently predominant approaches of Second Language Acquisition (SLA), namely the psycholinguistic and socio-cultural theories that view interaction as the essential component for language learning. In the case of psycholinguistics (Gass, 1997), interaction helps learners activate the individual cognitive processes that allow them to access the comprehensible input they need to further advance in the acquisition of L2, whereas in the socio-cultural approach (Lantolf, 2000) social interaction allows interlocutors to organize their cognitive processes that assist them in the coconstruction of knowledge about the L2. Although the importance of social interaction is underlined in both major views of language learning, psycholinguistics takes a more cognitive and individual perspective, whereas socio-cultural theory comes across on a more global and social dimension.

In the past three decades Psycholinguistics, which is considered the more traditional perspective on language learning, has brought forth a broad range of studies based on the Input Hypothesis, the Output Hypothesis and the Interaction Hypothesis. From the early 1980s, when Krashen claimed that language learners needed to receive comprehensible input slightly above their competence level $(i+1)$ so that they could progress in their learning, there have been debates on not only the need for input, but also on output and interaction to develop proficiency in a foreign or second language. According to Swain (1985), learners' output allows them to notice the gap of linguistic knowledge that exists between what they want to communicate and what they can communicate. In the process of producing language, learners test their hypothesis about the organization of the language system and once they have attempted to convey a certain message they can reflect on the interlocutors' responses and finally modify their language use. Together with the output hypothesis, the interaction 
hypothesis has postulated that interactive modifications (e.g., engaging in cooperative dialogue, asking and answering, and the use of clarifications) in native or native-like speaker input to non-natives are facilitative and necessary for SLA. Furthermore, the non-native speaker's role in the process of negotiating meaning (i.e., arriving at mutual understanding through confirmation and comprehension checks, as well as clarification requests) is considered crucial to the acquisition process (Hall \& Verplaetse, 2000).

The revival of Vygotsky's socio-cultural theory (1978), which stems from his work at the beginning of the twentieth century, has brought about studies that have provided strong evidence of an intrinsic link between language activities and language development. According to linguists from a socio-cultural perspective, learning occurs first between people (inter-mental), and then within the individual (intra-mental). Therefore, involvement in frequent and significant social activities with more competent language users is essential for learning to happen. Two of the main themes identified in Vygotsky's studies that may be applied to SLA are: mediation and social learning. Mediation describes how tools or cultural artefacts, such as language, transform human action and influence the way people perceive the world. Social learning is explained by the metaphor of the zone of proximal development (ZPD), which Vygotsky defined as the difference between what a person can achieve when acting alone and what the same person can accomplish when acting with support from someone else and/or cultural artefacts. Lantolf (2000: 17) states that some researchers have assumed that ZPD necessarily involves interaction between an expert and a novice in which the expert eventually transmits specific abilities to the novice through social interaction. In L2 or foreign language (FL) instruction, the teacher or other more competent users of the language act as the experts, while the students or less competent users act as the novices. The language development derived from the interactions of expert-novice has also been referred to as scaffolding, in which the novices are able to carry out activities that they would not have been able to without the assistance of the expert (Lantolf and Thorne, 2006). Other linguists with a socio-cultural perspective conceive the ZPD as the collaborative construction of opportunities for learning, which can be found in classrooms with a communicative and/or task based approach.

\subsection{The sociological realm - social demand for language learning}

The attitude towards the nature of language and how we believe it is learned by foreign (FL) or second language (L2) learners has been influenced undoubtedly by the demand for its use. In the case of English, the demand for its use has progressively increased throughout the last century and the first decade of the new millennium, which certainly is due to its condition as the lingua franca for academic and professional communication (see Pamela Faber's article in this issue). At the turn of the century, Alcaraz (2000:11) claimed:

In the last decades of the twentieth century the role of English as the lingua franca of the professional and academic world, on the one hand, and the interdisciplinary, functional and communicative view of language, on the other, have encouraged experts to inquire into the theoretical and applied aspects of English for professional and academic purposes. 
In the first decade of this new millennium, ELT research and practice has continued to take a turn towards a more specific view on how the use of this global language can be taught and learned by L2/FL learners, especially in European higher education. Many studies within the fields of English for Specific Purposes (ESP) and/or English for Academic Purposes (EAP) have focused on the academic and professional genres, i.e., the types of texts used for written and oral communication. However, with the advent of the digital era and, the pervasiveness of technology, genre studies have taken on other dimensions. The tools for communication or cultural artefacts of the twenty-first century are multimodal, that is, they include numerous modes of representing and communicating meaning (Kress, 2010). Therefore, it is no longer enough to study the written or spoken texts and their underlying meanings. We now need to take into account not only the verbal mode, but also the images, writing, layout, sound, gestures, speech and 3D objects that characterize the diverse mediating tools and resources (Internet, web pages, blogs, learning management systems (LMS), social networks, digital portfolios, linguistic corpuses, etc.) that humans use in present day communication.

\section{References}

Alcaraz Varó, Enrique (1990): Tres paradigmas de la investigación lingüística. Alcoy: Ariel. . (2000): El inglés profesional y académico. Madrid: Alianza Editorial.

Gass, Susan (1997): Input, interaction and the second language learner. Mahwah, New Jersey: Lawrence Erlbaum Associates.

Hall, Joan K. \& Loorie S. Verplaets (Eds.). (2000): Second and foreign language learning through classroom interaction. Mahwah, New Jersey: Lawrence Erlbaum Associates.

Kress, Gunther (2010): A social semiotic approach to contemporary communication. London: Routledge.

Lado, Robert (1964): Language teaching: A scientific approach. New York: McGraw Hill.

Lantolf, James P. (Ed.). (2000): Sociocultural theory and second language learning. New York: Oxford.

Lantolf, James P. \& Steven L. Thorne (2006): Sociocultural theory and the genesis of second language development. Oxford: Oxford University Press.

Swain, Merill (1985): "Communicative competence: Some roles of comprehensible input and comprehensible output in its development". In S. Gass \&C. Madden (Eds.) Input in second language Acquisition. Cambridge: Massachusetts: Newbury House.

Vygotsky, Lev S. (1978): Mind in Society. Cambridge: Harvard University Press.

\section{ELT in European higher education today: influential legislations, technological advances and methodologies}

As we have previously mentioned, the present issue of the RAEI focuses mainly on recent approaches to ELT in higher education contexts. In fact, this is a key issue nowadays since the European Higher Education System has been facing a major process of adaptation, regularization, and Europeanization that has posed many challenges, not only on national curricula but also, and most importantly, on the methodology and the learning strategies 
employed in ELT. Needless to say that English has become the lingua franca of academic communication and thus, most European universities are implementing Content and Language Integrated Learning (CLIL) courses and fostering English as the vehicular language not only in regular courses, but also as the language of dissertations and research.

The Bologna process is primarily focusing its attention on creating a system of comparable undergraduate and graduate degrees that are organized in a first cycle lasting three/four years followed by a second cycle that may award a master's and/or a PhD. The first cycle, as the Bologna Declaration and subsequent communiqués declared (Council of Europe, 2001, 2003, 2005, 2007, 2009), must satisfy the necessities of the European labour market, whereas the second cycle should lead to specialization and the contribution of unique and relevant research in the case of a PhD. Thanks to the European Credit Transfer System (ECTS) and mobility schemes, the European Higher Education Area (EHEA) aims to promote free circulation of students, lecturers, administrative staff and researchers; thus, fostering the development of a common tertiary culture and, at the same time, improving the necessity of learning European languages and enlarging mutual cultural knowledge. Lastly, a further stage imposed by the Bologna declaration that comes across in all the statements of the tertiary system, is the necessity of establishing a quality assurance system based on peer-revision by means of which all degrees are made comparable and high quality standards are enforced. The first ten years of the Bologna declaration was celebrated in 2010. In the Budapest-Vienna declaration (Council of Europe, 2010) the Ministers of Education of the countries involved in the process declared the great advancement undertaken towards the creation of a common EHEA, and how the process although not fully completed, has proved to be an unprecedented effort of cooperation and mutual understanding. The 2010 Budapest-Vienna declaration established a new agenda for the second decade of the millennium and the first results will be studied in May 2012 (Council of Europe, 2010).

As the declaration highlights, this whole process, which has been made possible due to the key commitment of the signatory countries has, on the whole, created an atmosphere of acceptance and mutual trust. Cooperation is fostered by pointing out Best Practices, not only in the process of implementation of the new degrees, but also on a methodology based on Constructivism and Humanism that tries to cater for the young Europeans' learning and labour necessities. European university students are re-defined as "competent, active and constructive partners" (Council of Europe, 2001) whose roles in the system break the old rules. They are now changing from mere passive receptors of knowledge towards becoming dynamic stakeholders who make decisions, collaborate, share, travel and learn and are indeed able to enlarge their learning beyond university in a life-long learning cycle.

These grounds are extremely important in a moment of global crisis that we are currently experiencing in Europe. Improving quality and promoting creativity and innovation in our tertiary system have been determined as the key factors to develop viable strategies for economic recovery (Council of Europe, 2009). The aim of tertiary institutions, which naturally focuses on the preparation of students for their future life, in this particular context must emphasize the acquisition of a broad knowledge base and the stimulation of research, creativity, and innovation in their areas of specialization, but without forgetting the necessary role of universities in the construction of active European citizens. 
Regarding methodology, the ECTS has provoked a remodelling of the concepts of understanding and learning, which in turn has been revealed as the starting point of a new vision centred on the students' learning and workload. Thus, students' learning is not simplistically viewed as an activity performed within the four walls of a classroom, but as a flexible concept that encompasses the work done before, in and after the lessons, transversal skills, the use of Information and Communication Technology (ICT), extra-curricular activities, reflection, autonomous or collaborative work, specific learning paths, etc. Furthermore, English, as our opening article posits, has become the lingua franca of the EHEA. For ELT it also implies the commitment of preparing the students in one of the most fundamental transversal skills: intercultural communication. International openness and mobility, two of the basic criteria of the construction of the EHEA, cannot be fulfilled without an adequate training in languages. Most universities have, therefore, integrated compulsory English courses in their curricula so as to be sure that most of their undergraduate students end the first cycle of higher education studies with at least an intermediate level (B2). This learning outcome has also fostered the creation of CLIL courses that allow the students not only to learn a language, but also to use this language in their professional sphere, thus completing the other Bologna objective, namely the creation of a common European labour market.

Within this framework, ELT teachers at European tertiary institutions are facing numerous challenges. On the one hand, the new structures of the cycles have forced a major change in most degrees involving a new allocation of curricula, courses, and workload. On the other, although some voices have been raised against the reforms, we have been witnesses to a great effort of adaptation and implementation of the main principles of the Bologna process. This issue of the RAEI collects some of these efforts and presents some of the best practices carried out in Spain within the field of ELT.

Another of the greatest efforts accomplished in the area of languages at European level has been the establishment of a Common European Reference Framework (CEFR). This framework presents a model for scaling language learning based on a thorough reflection on competence, methodology and assessment practices. The main aim is to offer a comprehensive transparent and coherent system that could be applied to establish comparable scales to describe language use and levels of proficiency and qualifications across Europe. At the moment, a fixed consensus on the required language levels at all universities has not been established; therefore, further work is needed on the implementation of the CEFR at tertiary institutions, as well as, on the coordination and recognition of previous knowledge acquired both in formal and non-formal education.

As this short introduction to the learning and teaching of English in the European context tries to show, there have been momentous changes in tertiary education that have influenced new approaches and methodologies in ELT. Adaptations have been necessary to share good practices and implement proven methodologies and strategies. Most of the articles included in this issue share this common aim and on a whole contribute to highlight the relevance of ELT in the construction of a cohesive EHEA in which information and research can be shared and people move freely. 


\section{References}

Council of Europe (2001): The Prague Communiqué: TOWARDS THE EUROPEAN HIGHER EDUCATION AREA. Communiqué of the meeting of European Ministers in charge of Higher Education in Prague. Online document [Last accessed 15 January 2011]

. (2001): Common European Framework of Reference for Languages: Learning, teaching, assessment. Cambridge: C.U.P.

. (2003): Berlin communiqué: Realising the European Higher Education Area

[http://www.wg.aegee.org/ewg/berlincommunique.htm] (last accessed 15-1-2011).

. (2005): The European Higher Education Area Achieving the Goals.

[http://www.bologna-bergen2005.no/Docs/00-Main_doc/050520_Bergen_Communique.pdf] (last accessed 15 January 2011).

. (2007): Towards the European Higher Education Area: responding to challenges in a globalised world.

[http://webarchive.nationalarchives.gov.uk/20100202100434/].

[http://www.dfes.gov.uk/londonbologna/uploads/documents/LondonCommuniquefinalwith Londonlogo.pdf].

. (2009): Communiqué of the Conference of European Ministers Responsible for Higher

Education, Leuven and Louvain-la-Neuve, 28-29 April 2009.

[ http://www.ond.vlaanderen.be/hogeronderwijs/bologna/conference/documents/Leuven _Louvain-la-Neuve_Communiqu\%C3\%A9_April_2009.pdf] (last accessed 15-1-2011). . (2010): Budapest-Vienna Declaration on the European Higher Education Area.

[http://www.ond.vlaanderen.be/hogeronderwijs/bologna/2010_conference/documents/

Budapest-Vienna_Declaration.pdf].

\section{The ELT research contributions of this special issue}

In the past ten years, as is clearly established in the introductory article and the research contributions of this special issue on ELT, the teaching of English has continued on its course of finding ways of facilitating language learning. In this special issue of RAEI we situate English as the lingua franca in the introductory article, and present the main areas of ELT study that the contributions deal with, namely Corpus linguistics (CL), Content and Language Integrated Learning (CLIL), Information and Communications Technology (ICT), Learning Autonomy, and Assessment. As mentioned previously, ELT today has a strong focus on studies to improve teaching and learning practices in English for Academic Purposes (EAP), which is reflected in the majority of the articles found in this volume. It is interesting to note that many of them refer to the need for best practice in the process of forming competent users of the lingua franca in the technical fields of tertiary education.

This special issue on ELT begins with Pamela Faber's introductory article, "English as an Academic Lingua Franca" reminding us of the benefits of a common language for international communication and knowledge transfer in the academic world. Furthermore, it clearly shows that English as a lingua franca (ELF) should be considered as a convenient tool and not as a threat to the plurilingualism of Europe. Subsequently, it can be seen as an instrument to further the competitiveness of Spanish universities, engineers and scientists in 
our highly globalized society.

The focus then shifts to the teaching of English Academic and Professional Purposes (EAPP), a term coined by Enrique Alcaraz, which is the basis for Keith Stuart and Ana Botella's article. They take a corpus linguistic approach to EAPP in the Spanish University System, taking the nuances of the European Higher Education Area into account. This methodological framework takes the form of personalized learning and continuous evaluation in use in the ALVA Project (Aprendizaje de Lenguas con Valor Añadido - Value Added Language Learning), where the corpus leads to the creation of teaching materials. This change to tertiary EAPP courses also implies a change in the skills needed to teach such courses which are briefly summarized at the end of the study.

It is followed by research done by Miguel Fuster and Begoña Clavel where they also delve into the importance of corpus linguistics (CL) in teaching practices. In this analysis they highlight the importance of Data Driven Learning (DDL) due to its relevance in applied linguistics literature, and examine in detail the advantages and drawbacks in the implementation of CL in higher education. Finally, the difficulties concerning the implementation of CL in the classroom are discussed as an awareness of the limitations of CL is necessary to contribute to its future success.

Next, María Luisa Carrió Pastor and David Perry discuss an ongoing project in which content teachers and language teachers collaborated in order to design online teachinglearning materials which integrated subject matter and language tasks. Their research has shown that CLIL and Collaborative Approach (CA) should be implemented to teach a second language, and a dynamic tool such as the Internet should be used as a vehicle as higher education students are now used to technology and demand updated materials. Consequently, teachers should take advantage of online materials and communication tools. Another result from the study has shown that this methodology reinforces students' self-esteem and collaborative behaviour both in the classroom and online.

Another view on CLIL comes to the forefront in Carmen Sancho Guinda's "The emergent role of mind-mapping in CLIL instruction: Textual cognitive resources in engineering lectures" where she takes a look at conceptual maps as an academic skill. To this end, a small case study in engineering courses aims to reflect on the implications of lecturers' textual choices for the note taking habits of engineering students and ultimately for their representation of contents. The results suggest an influence of lecturing style on note taking quality and evidences several lecturing deficiencies at the rhetorical level that may hamper the practice of conceptual mapping.Following along the lines of autonomy, Ruth Wilkinson at the University of Castilla la Mancha describes the measures taken, and the reactions to the process of an action research project with English degree students. The aim of the project was to raise students' awareness of the need to be less dependent on their teachers and to provide the reflective and interactive scaffolding necessary to enable them to take greater responsibility for their own learning. The extensive use of student portfolios for self, peer and teacher evaluation served this purpose. She concludes by discussing the lessons learned and proposing a number of guidelines to be taken into account when attempting to promote autonomy in a similar context.

More on assessment and autonomy is also discussed in "Self-assessment based on 
language learning outcomes: a study with first year engineering students"by Pilar Durán Escribano and Joana Pierce McMahon. A pilot experience with Technical English mining engineering students regarding learning outcomes and competences was designed and a new approach to language learning is discussed, with special attention to learner reflection and self-assessment practices. This means a change in teaching focus, from an input model to an output one, which promotes self-assessment in a flexible curriculum, in this case adapted to student's language profile. The conclusions of the study reinforce the concept of measurable achievements expected in the EHEA.

In the final article, Marian Amengual Pizarro focuses on the washback effects of a highstakes English Test (ET), the Spanish university access exam: selectividad, on the teaching of English. The study shows how high-stakes tests have started to be exploited to modify instruction and achieve beneficial washback on the following aspects of teaching: curriculum, materials, teaching methods, as well as, teaching feelings and attitudes. One of the interesting results of the study regards a speaking and a listening component in the design of the new ET due to be implemented in 2012; teachers expect this will help solve the mismatch between the communicative approach teachers seem to value and the skills so far evaluated in the ET. 